\title{
Thermal network of coupled building and electrical appliances
}

\author{
Herie Park ${ }^{1, a}$, Marie Ruellan ${ }^{2}$, Rachid Bennacer $^{3}$ and Eric Monmasson ${ }^{2}$ \\ 1 Institute of Industrial Technology, Yeungnam University, Korea \\ 2 SATIE CNRS UMR8029, University of Cergy-Pontoise, France \\ 3 LMT CNRS UMR 8535, École Normale Supérieure-Cachan, France
}

Received 13 April 2015, Accepted 2 July 2015

\begin{abstract}
As power density of electrical appliances in a building sector grows up, its thermal effect also increases especially within a well-insulated building. In order to investigate the heat gain of these appliances, this paper proposes a dynamic thermal model of electrical appliances which is embedded in a building thermal analysis by using thermal network method. For this, thermal-electrical analogy and a static model and a dynamic model of electrical appliance coupled to a thermal network of a building are presented. As applications, a monitor and a computer are selected and their thermal models are adapted to a building model. Finally, their thermal influence is observed by experimental results and simulation one.
\end{abstract}

Key words: Thermal network / thermal-electric analogy / thermal building / heat gain of electrical appliances / dynamic model

\section{Introduction}

A building has a complex thermal interaction with its interior and exterior conditions. Behavior of occupants, installation and utilization of sub-systems, structures and materials, and meteorological and geographical data lead different thermal characteristics and dynamic behaviors of a building. Since these factors also influence energy performance and building efficiency, it is necessary to analyze them in detail for more accurate thermal evaluation [1].

In order to bring more precise advancements and quantifications, diverse thermal modeling and analysis methods have been proposed $[2,3]$. As one of the dynamic methods, thermal network has been used from mid-1980s for the reason of its simplicity and its accuracy to compose the heat source and the structure of the building at the same time [4-7]. This method is based on the energy balance equation (first law) and the analogy between thermal and electrical systems. By using this method, it is possible to illustrate heat transfer phenomena of building systems and heat gain/loss corresponding to solar radiation, occupants, infiltration/ventilation, and equipment by electrical components and sources.

In literature, the auxiliary heat sources such as solar gain, dissipated heat of electrical equipment and appli-

${ }^{a}$ Corresponding author: park.herie@gmail.com ances, metabolic heat are represented by a current source in thermal network. It means that these sources are used to be considered as a static value. However, these sources can also have their thermal characteristics and be dynamically modeled expressing heat phenomena [8-12]. Especially within a well-insulated building model for achieving low energy consumption for heating and cooling the space (signal), thermal effect of an extra heat source (noise) is more important because the heat loss through the building envelopes becomes less than in conventional buildings. We reach situation of comparable levels of signal and noise. Therefore, it is necessary to model the sources in more detail for low energy buildings. In addition, as a simulation interval becomes shorter, conventionally ignorable thermal dynamics of heat sources have to be also taken into account during building thermal analysis.

In this paper, we present how electrical appliances influence the building thermal behavior by representing thermal-electric analogy and show a dynamic model of electrical appliances which exhibit thermal properties and its effect on a building. It aims to show the necessity of dynamic thermal modeling of electrical appliances for a further building energy simulation. Section 2 recalls thermalelectric analogy and thermal network and applies them to a building and electrical appliances coupling. Section 3 describes applications of the proposed thermal model of a monitor and a computer within a well-insulated room and 
shows their thermal effect by experimental and simulation results. Finally, Section 4 concludes this work.

\section{Methodology}

\subsection{Thermal-electric analogy}

Thermal models of a building and its sub-systems are represented by electrical circuits including electrical components and electrical sources. The thermal dynamics of the systems are analyzed in accordance with the electrical dynamics of the corresponding electric circuits. Table 1 lists the analogy according to sources and elements of each system.

\subsection{Thermal Network}

Based on the first principle of thermodynamics, a heat balance of a building can be deduced as:

$$
\begin{aligned}
& \Phi_{\text {heating }}+\Phi_{\text {sun }}+\Phi_{\text {metabolism }}+\Phi_{\text {appliance }}+\Phi_{\text {recovery }} \\
& =\frac{\mathrm{d} U_{\text {stored }}}{\mathrm{d} t}+\Phi_{\text {envelope }}+\Phi_{\text {vent/infiltration }}+\Phi_{\text {hot water }}
\end{aligned}
$$

where $\Phi_{\text {heating }}$ is the energy contributed by electricity or fuels for heating/cooling a building, $\Phi_{\text {sun }}, \Phi_{\text {metabolism }}$, $\Phi_{\text {appliance }}, \Phi_{\text {recovery }}$ are respectively the free internal heat gains of solar energy, metabolism of occupants, heat dissipation of electrical appliances, and the recovered heat flux. $U_{\text {stored }}$ is the stored energy within a building, $\Phi_{\text {envelope }}$ is the transmission heat loss through building envelopes (walls, windows, ceilings, floors and doors), $\Phi_{\text {vent/infiltration }}, \Phi_{\text {hot_water }}$ are the heat losses by ventilation/infiltration and hot water consumption, respectively.

In order to underline thermal-electric coupling between a building and an electrical appliance, we consider only one heat source of an electric appliance and heat loss via envelope of the building in this study. The obtained heat balance model is therefore,

$$
\Phi_{\text {appliance }}=\frac{\mathrm{d} U_{\text {stored }}}{\mathrm{d} t}+\Phi_{\text {envelope }}
$$

Equation (2) can be deduced by thermal characteristics of the building which are thermal resistance $R_{\mathrm{th}}$ and thermal capacitance $C_{\text {th }}$ as follows:

$$
\Phi_{\text {appliance }}=C_{\mathrm{th}} \frac{\mathrm{d} T_{i}}{\mathrm{~d} t}+\frac{1}{R_{\mathrm{th}}}\left(T_{i}-T_{e}\right)
$$

where, $T_{i}$ and $T_{e}$ are the interior and exterior temperatures of the building. According to the thermal-electric analogy, this model is represented by a thermal network as illustrating in Figure 1.

The heat flux of the electrical appliance $\Phi_{\text {appliance }}$ can be also thermally modeled as follows.

$$
\begin{aligned}
& \Phi_{\text {appliance }}=P_{\text {elec }} \\
& \Phi_{\text {appliance }}=\frac{1}{R_{\mathrm{ap}}}\left(T_{\mathrm{ap}}-T_{i}\right)=P_{\text {elec }}-C_{\mathrm{ap}} \frac{\mathrm{d} T_{\mathrm{ap}}}{\mathrm{d} t}
\end{aligned}
$$

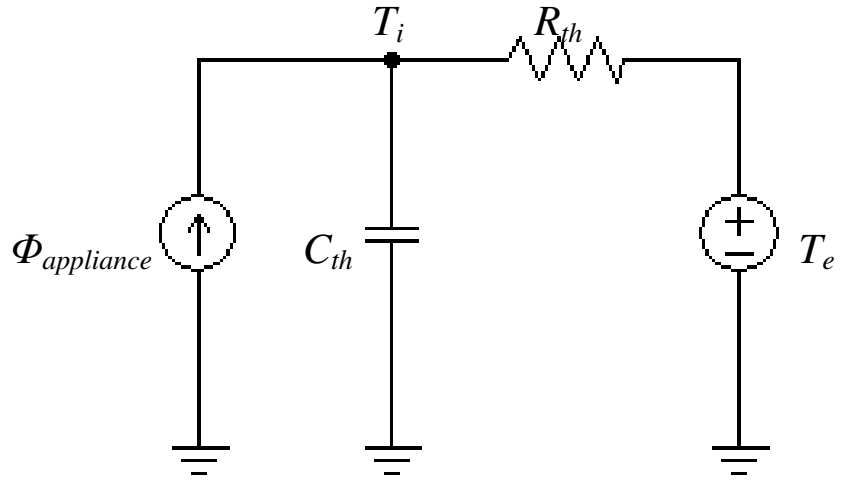

Fig. 1. Thermal network of a simplified building model.

where $P_{\text {elec }}$ is the supplied power of electrical appliance. $R_{\text {ap }}$ and $C_{\text {ap }}$ are thermal parameters of an electrical appliance, thermal resistance and thermal capacitance.

First, Equation (4) describes a conventional static model. In this model, we do not take account into the thermal dynamics of the used electrical appliance and suppose that all electrical energy is converted to thermal energy without thermal delay. Second, Equation (5) shows a dynamic model of an electrical appliance including the thermal characteristics of appliances so as to obtain more accurate results. As stated above, these models can be represented by a thermal network. The scheme is shown in Figure 2.

\subsection{Parameter identification method}

In order to analyze the model behavior, it needs to identify the parameters of the proposed model. If relevant physical properties of the system have been already known, the model parameters can be easily obtained. On the other hand, if the properties are insufficient to identify model parameters, available experimental data and parameter identification methods can be applied for the computational parameter identification.

In this study for a building model and electrical appliances, there are insufficient physical properties for parameters, but the driven physical principles are known. Therefore we use a grey-box method which obtains the unknown parameters by taking into account experimental input and output data of the system and a given physical principle, here, the first principle of thermodynamics. The input/output data of a coupled system are shown in Figure 3.

As one of the parameter identification method, we applied a linear parametric first-order model, which is explained in reference [12]. Briefly, a stochastic differential equation in continuous time is developed from the given basic principle. Then, a discretization of the corresponding differential equation is obtained. After that, parameters via any linear parametric model are estimated and the results obtained by experiment and simulation are compared in order to validate the model and 
H. Park et al.: Mechanics \& Industry 17, 102 (2016)

Table 1. Thermal-electric analogy.

\begin{tabular}{ccccc}
\hline & \multicolumn{2}{c}{ Thermal System } & \multicolumn{2}{c}{ Electric System } \\
\cline { 2 - 5 } Parameter & Unit & Parameter & Unit \\
\hline \multirow{2}{*}{ Source } & Temperature $T$ & {$[\mathrm{~K}]$} & Voltage $V$ & {$[\mathrm{~V}]$} \\
& Heat flux $\Phi$ & {$[\mathrm{W}],\left[\mathrm{J} . \mathrm{s}^{-1}\right]$} & Current $I$ & {$[\mathrm{~A}],\left[\mathrm{C} . \mathrm{s}^{-1}\right]$} \\
\hline \multirow{3}{*}{ Element } & Conductivity $k$ & {$\left[\mathrm{~W} .(\mathrm{Km})^{-1}\right]$} & Conductivity $\sigma$ & {$\left[\mathrm{A} .(\mathrm{V} . \mathrm{mm})^{-1}\right]$} \\
& Thermal resistance $R_{\text {ther }}$ & {$[\mathrm{K} / \mathrm{W}]$} & Electrical resistance $R_{\text {elec }}$ & {$[\Omega],\left[\mathrm{V} . \mathrm{A}^{-1}\right]$} \\
& Thermal capacitance $C_{\text {ther }}$ & {$[\mathrm{J} / \mathrm{K}]$} & Electrical capacitance $C_{\text {elec }}$ & {$[\mathrm{F}],\left[\mathrm{C} . \mathrm{V}^{-1}\right]$} \\
\hline
\end{tabular}
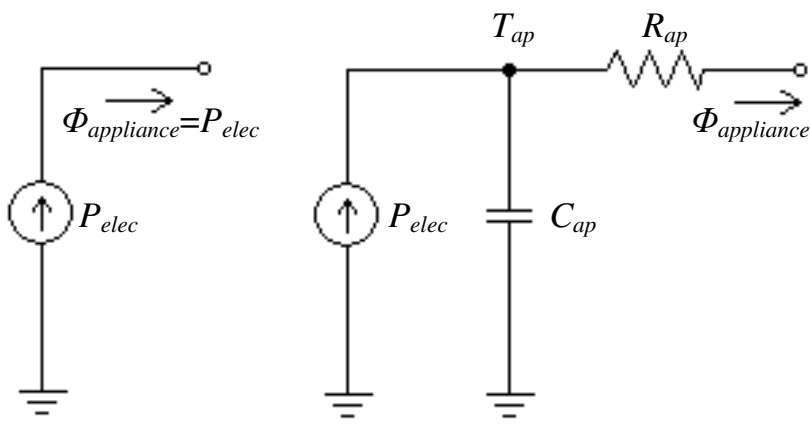

Fig. 2. Thermal networks of an electrical appliance.

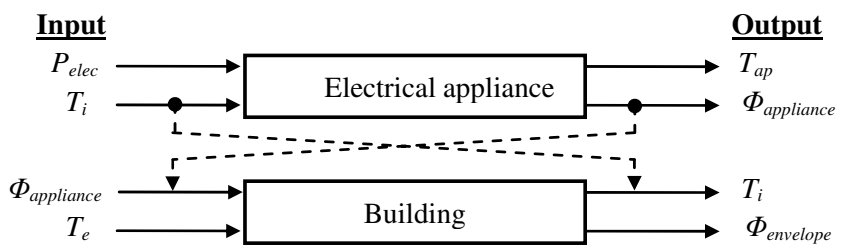

Fig. 3. Input/output data of coupled systems.

parameters. Among several parametric models, we use Auto-Regressive eXogeneous input (ARX) model for its simplicity.

\section{Application}

In this section we investigate the thermal interaction between a building and electrical appliances. Based on the proposed thermal network models and parameter identification methods, we obtained thermal parameters of a building and electrical appliances.

As a test building, we used a well-insulated room (size $4 \times 2.4 \times 2.4 \mathrm{~m}^{3}$ ), which wall is made up polyurethane and stainless steel sheet. It has a door (length: $0.9 \mathrm{~m}$, height: $1.9 \mathrm{~m}$ ) with the same material to the wall and a small window (length: $0.3 \mathrm{~m}$, height: $0.5 \mathrm{~m}$ ). It has four incandescent lamps $((60 \mathrm{~W}+75 \mathrm{~W}) \times 2 \mathrm{EA})$ which are positioned on upper side of walls. The details of this room can be found in reference [12]. This room is represented by a given building model as 1R1C thermal network and its global thermal parameters are $R_{\mathrm{th}}=57.8 \times 10^{-3}{ }^{\circ} \mathrm{C} / \mathrm{W}$ and $C_{\mathrm{th}}=623 \mathrm{~kJ} /{ }^{\circ} \mathrm{C}(R . C=10 \mathrm{~h})$.

As candidates of electrical appliances, a monitor and a computer were selected for this study. These appliances are widely used in commercial, official and residential
Table 2. Thermal parameters of electrical appliances

\begin{tabular}{ccc}
\hline & Monitor & Computer \\
\hline$R\left({\left.\mathrm{~K} . \mathrm{W}^{-1}\right)}^{-1}\right.$ & $2.5 \times 10^{-3}$ & $2.8 \times 10^{-3}$ \\
$C\left(\mathrm{~kJ} . \mathrm{K}^{-1}\right)$ & 36.7 & 13.7 \\
$R . C(\mathrm{~s})$ & 91.75 & 38.36 \\
\hline
\end{tabular}

buildings. The supplied power of the monitor and the computer are respectively, 27 and $58 \mathrm{~W}$. Their thermal parameters which are thermal resistance and capacitance (monitor $R_{m}, C_{m}$ and computer $R_{c}, C_{c}$ ) were estimated by an ARX model parameter identification method and are listed in Table 2.

Using the proposed thermal network and its parameters, heat fluxes of the monitor and the computer are obtained as shown in Figures $4-5$. The heat fluxes of a static model and a dynamic model are presented. As modeled above, the heat flux of a static model is the same to the power consumption profile of the appliances. However, dynamically modeled heat flux dissipated by appliances is not considered as the one of the static model, because the dynamic model implies remarkable thermal characteristics of the appliance. Since the dynamic thermal model of an electrical appliance has its thermal capacitance, heat is charged and discharged to the appliance at transient state. Moreover, due to its thermal resistance of the appliance within the dynamic model, the heat flux is consequently influenced by temperature difference between the electrical appliance and the room at steady state. According to energy conservation, electrical energy is all converted to heat and the quantities of the energy of a static model and a dynamic model are the same. However, due to the existence of the thermal capacitance and the thermal resistance in a dynamic model, the profiles of the dissipated heat flux between two models are different. This difference leads different building thermal behavior which is mainly controlled during the identification by the building time characteristic $(10 \mathrm{~h})$.

Figures 6-7 depict indoor temperatures of the test room influenced by the heat gains of a monitor and a computer, respectively. In these cases, there are no significant difference of simulated temperature obtained by a static model and a dynamic model of electrical appliances. It is due to small difference of heat fluxes of the models against thermal characteristics of the building. Since the usage period of the appliances is too long so that indoor temperature remains at steady state for a long time and that of thermal influence of the both models becomes identical. If there are more frequent on/off 


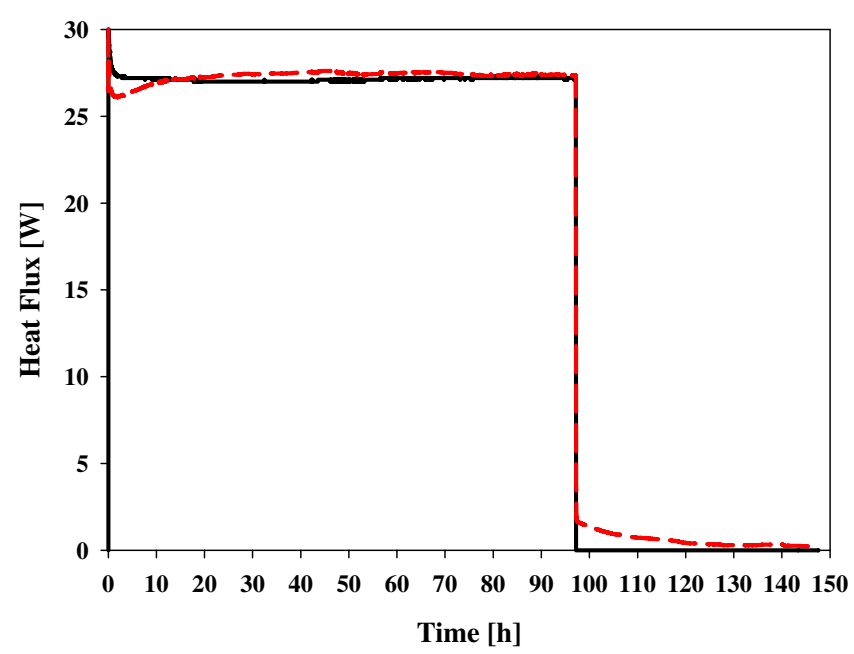

Fig. 4. Monitor heat flux

(_ Static model, -- Dynamic model).

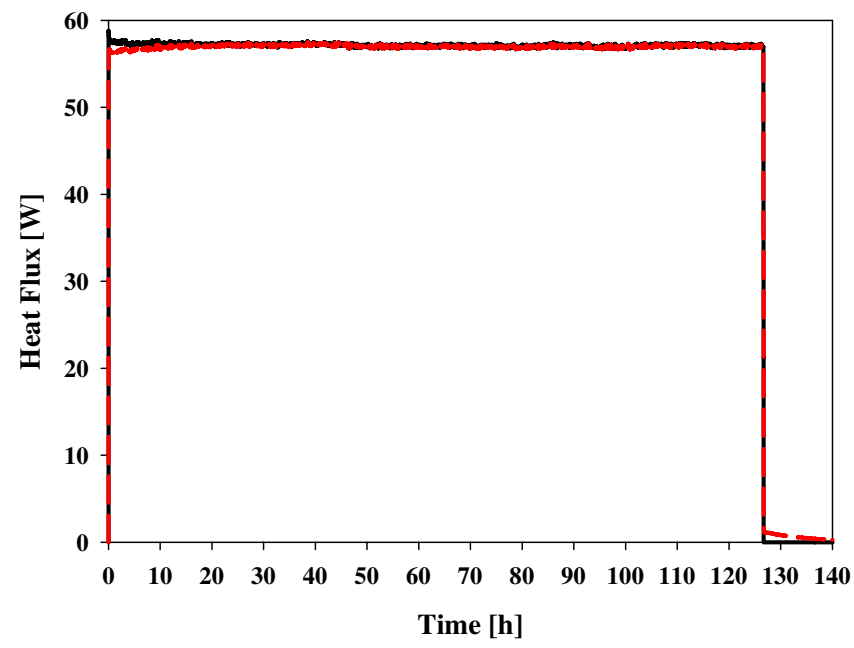

Fig. 5. Computer heat flux

(_ Static model, -- Dynamic model).

functions of the appliances, we can observe more difference of thermal effect caused by the two different models. Moreover, if the injected power of appliances is relatively important, the difference of heat fluxes of different models can influence more considerably the building indoor temperature. For example, within an office or a computer room where many computational devices are placed, a dynamic model of these devices can provide more accurate thermal analysis results. In addition, as thermal capacitance of the appliance is bigger, the time constant of the model increases and the duration at transient state becomes longer. In this case, there is more different thermal effect of two models and we can recognize the necessity of the dynamic thermal modeling.

Figure 8 shows several evolutions of indoor temperature influenced by electrical appliances which are modeled by different thermal capacitances $\left(5,10,20 \%\right.$ of $\left.C_{\mathrm{th}}\right)$ and different power consumptions $(100,200,400 \mathrm{~W})$. As mentioned above, bigger thermal capacitance and higher

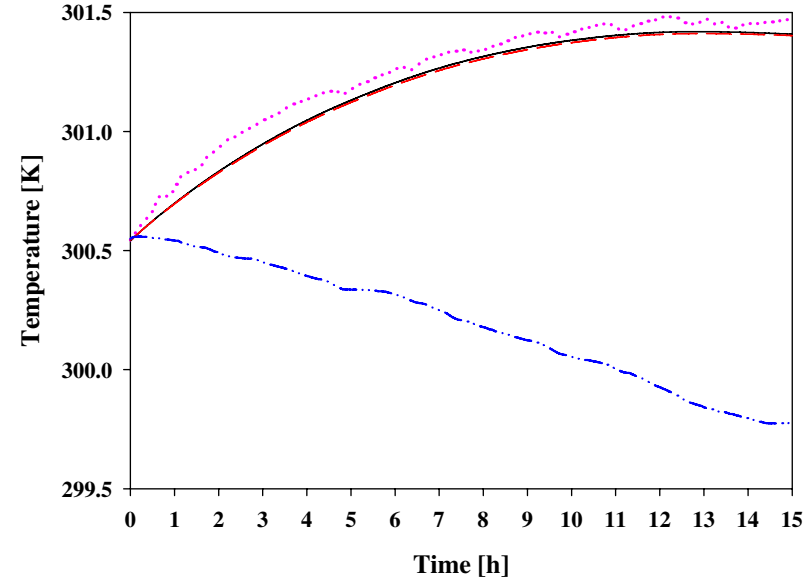

Fig. 6. Measured $T_{i}(\ldots)$ and $T_{e}(-\ldots)$ and simulated $T_{i}$ (_ Static model, -- Dynamic model) by a monitor.

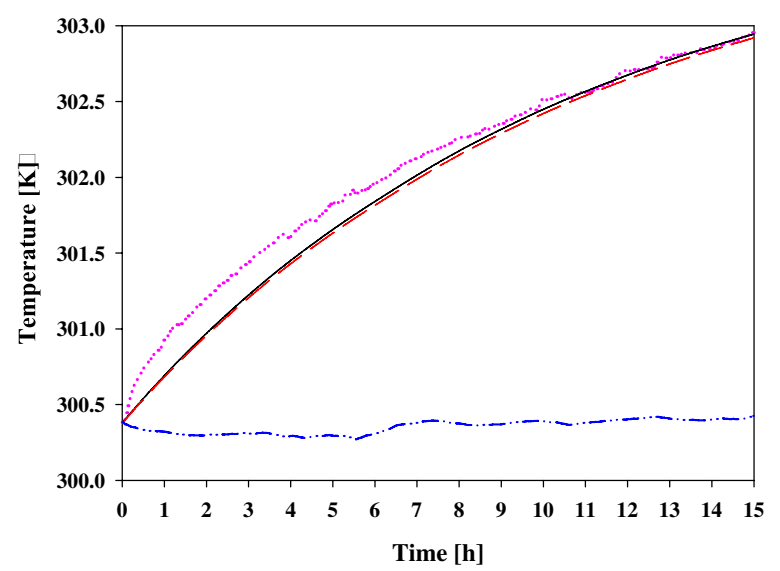

Fig. 7. Measured $T_{i}(\ldots)$ and $T_{e}(-\ldots)$ and simulated $T_{i}$ (_ Static model, _- Dynamic model) by a computer.

power consumption make more significant difference of heat flux profiles versus heat flux due to a static model and that leads more important difference of thermal behavior of a building.

\section{Conclusions}

This paper proposed a coupled thermal network of a building and electrical appliances for a thermal analysis of a building at transient and steady-states. Based on thermal-electric analogy and heat balance equation, a methodology of dynamic thermal modeling of a building and electrical appliances were presented. A simplified building model is first established. Then static and dynamic models of electrical appliances were coupled to the building model by using thermal network. For applications, a monitor and a computer were selected as one of the widely used appliances within a building sector. Their heat fluxes were simulated by static and dynamic models and their thermal influence was investigated within a well-insulated room. A static model showed a directly 

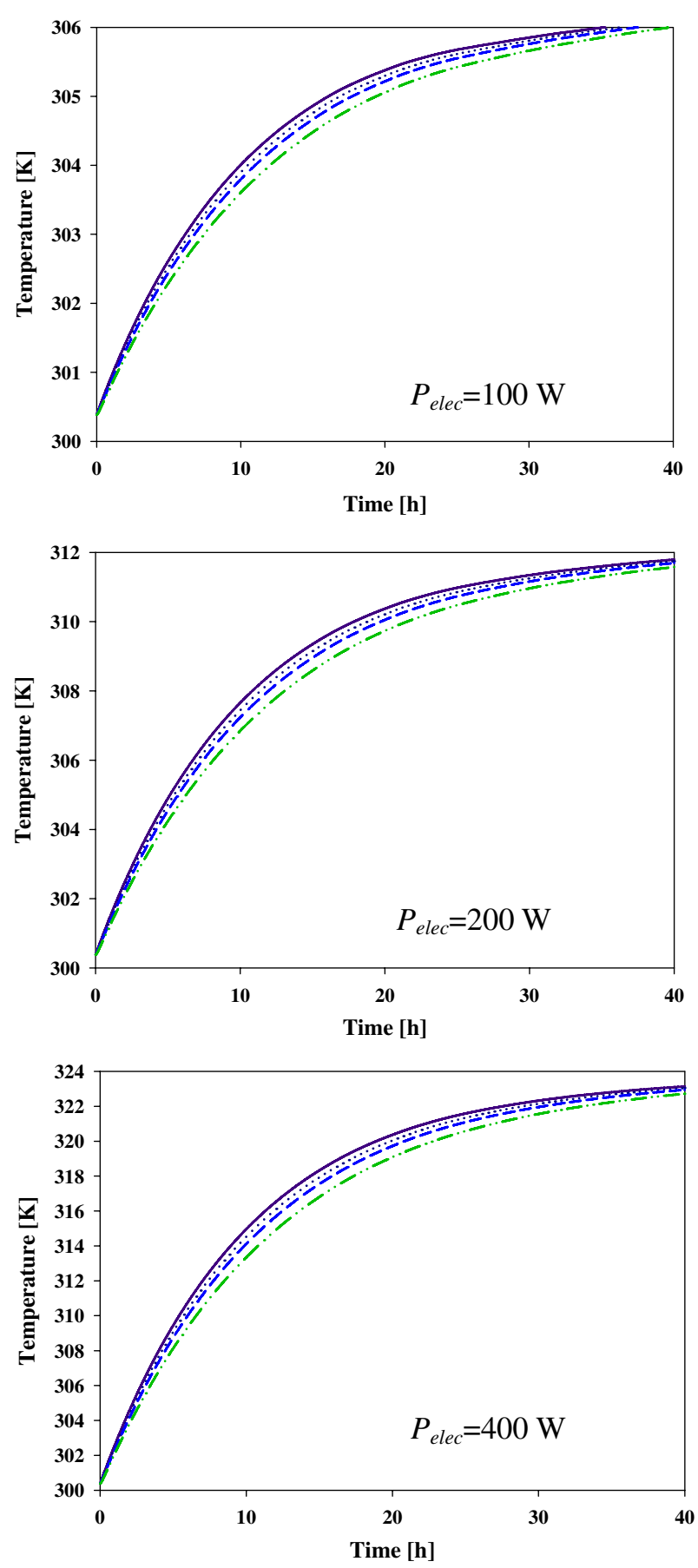

Fig. 8. Simulated indoor temperature (- Static model, $\ldots C_{\text {ap }}=5 \%$ of $C_{\mathrm{th}}--10 \%$ of $C_{\mathrm{th}}, \cdots-20 \%$ of $\left.C_{\mathrm{th}}\right)$.

converted heat flux of electrical appliances, of which original form was electric power. On the other hand, a dynamic model described dissipated heat of electrical appliances which was temporally influenced by thermal characteristics of the appliances and its adjacent temperature. For the cases of a monitor and a computer, there was no significant difference of thermal behaviors of the room once applied a static model and another case applied a dynamic model due to the relatively small quantity of injected elec- tric power to the appliances against thermal characteristics of the used building. However, through a parametric study of thermal capacitance and power consumption of an electrical appliance, it was observed that there is more important difference of thermal effect between a static model and a dynamic model on a coupled building thermal behavior and that dynamic thermal modeling is required to the conditions which electrical appliances have bigger thermal capacitance and consume higher power and that there are more frequent on/off functions.

As a further study, we will treat multi-characterized appliances within a building and investigate their thermal influence as a dominant heat source, not any more as ignorable noise.

\section{References}

[1] J.L.M. Hensen, Simulation for performance based building and systems design: some issues and solution directions, Proc. of 6th International Conference on Design and Decision Support Systems in Architecture and Urban Planning, 2002, pp. 186-199

[2] M.S. Al-Homoud, Computer-aided building energy analysis techniques, Building and Environment 36 (2001) 421433

[3] S. Wang, Y. Chen, Transient heat flow calculation for multilayer constructions using a frequency-domain regression method, Building and Environment 38 (2003) 45-61

[4] J.J. Roux, Proposition de modèles simplifiés pour l'étude du comportement thermique des bâtiments. INSA de Lyon, Thèse de Doctorat, 1984

[5] G. Fraisse, C. Viardot, O. Lafabrie, G. Achard, Development of a simplified and accurate building model based on electrical analogy, Energy and Buildings 34 (2002) 1017-1031

[6] G. Parnis, Building thermal modeling using electric circuit simulation, Master Thesis, University of New South Wales, 2012

[7] C. Ghiaus, I. Hazyuk, Calculation of optimal thermal load of intermittently heated buildings, Energy and Buildings 42 (2010) 1248-1258

[8] I. Hazyuk, C. Ghiaus, D. Penhouet, Optimal temperature control of intermittently heated buildings using Model Predictive Control: Part I - Building modeling, Building and Environment 51 (2012) 379-387

[9] F. Thellier, F. Monchoux, M. Bonnis-Sassi, B. Lartigue, Modeling additional solar constraints on a human being inside a room, Solar Energy 82 (2008) 290-301

[10] P. Bacher, H. Madsen, Identifying suitable models for the heat dynamics of buildings, Energy and Buildings 43 (2011) 1511-1522

[11] A.T. McDonald, S.H. Friskney, D.J. Ulrich, Thermal model of the dishwasher heater in air, IEEE Trans. Ind. Appl. 25 (1989) 1176-1180

[12] H. Park, M. Ruellan, N. Martaj, R. Bennacer, E. Monmasson, Generic thermal model of electrical appliances in thermal building: Application to the case of a refrigerator, Energy and Buildings 62 (2013) 335-342 